\title{
Root Dynamics of Muskmelon Transplants as Affected by Nursery Irrigation
}

\author{
José A. Franco ${ }^{1}$ \\ Departamento de Producción Agraria, Universidad Politécnica de Cartagena, Alfonso XIII 52, 30203 \\ Cartagena, Spain \\ Daniel I. Leskovar \\ Department of Horticultural Sciences, Texas Agricultural Experiment Station, Texas A\&M University, \\ 1619 Garner Field Road, Uvalde, TX 78801
}

\begin{abstract}
AdDitional INDEX WORDS. Cucumis melo, flotation irrigation, minirhizotron, overhead irrigation, stand establishment, transplant shock

Abstract. Containerized 'Lavi' muskmelon [Cucumis melo L. (Reticulatus Group)] transplants were grown in a nursery with two irrigation systems: overhead irrigation (OI) and flotation irrigation (FI). Initially, root development was monitored during a 36-day nursery period. Thereafter, seedling root growth was monitored either in transparent containers inside a growth chamber, or through minirhizotrons placed in the field. During the nursery period, OI promoted increased early basal root growth, whereas FI promoted greater basal root elongation between 25 and 36 days after seeding (DAS). At 36 DAS leaf area, shoot fresh weight (FW) and dry weight (DW), and shoot to root ratio were greater for OI than for FI transplants, while root length and FWs and DWs were nearly the same. Total root elongation in the growth chamber was greater for FI than for OI transplants between 4 and 14 days after transplanting. Similarly, the minirhizotron measurements in the field showed a greater root length density in the uppermost layer of the soil profile for FI than for OI transplants. Overall, muskmelon transplants had greater root development initially when subjected to overhead compared to flotation irrigation in the nursery. However, during late development FI transplants appeared to have a greater capacity to regenerate roots, thus providing an adaptive mechanism to enhance postplanting root development and to withstand transplant shock in field conditions. At harvest, root length density and yield were closely similar for the plants in the two transplant irrigation treatments.
\end{abstract}

Vegetable growers use containerized seedlings or transplants to enhance stand establishment, improve growth uniformity, promote earliness and increase yield. Most vegetable transplants are grown in greenhouses with overhead irrigation; however, subirrigation (flotation or ebb and flow) systems were reported to produce high-quality transplants of bell pepper [Capsicum annum L. var. annum (Grossum Group)] (Leskovar and Cantliffe, 1993; Leskovar and Heineman, 1994), tomato (Lycopersicon esculentum Mill.) (Leskovar et al., 1994; Wyatt, 1998), cabbage [Brassica oleracea L. (Capitata Group)] (Frantz and Welbaum, 1995a), and sweet corn (Zea mays L. var. rugosa Bonaf.) (Frantz and Welbaum, 1995b).

Understanding seedling root and shoot morphological and physiological responses to water management in the greenhouse throughout the nursery period is critical to optimize production of high-quality transplants. Transplant irrigation systems can influence root growth resulting in differences in lateral and basal root elongation (Leskovar, 1998; Leskovar and Stoffella, 1995), shoot water potential (Leskovar and Heineman, 1994), and mineral nutrient content (Biernbaum and Versluys, 1998). Shoot to root ratio can change rapidly in response to transient drought stress or during plant acclimation upon transplanting (Leskovar and Heineman, 1994). A reduction of this ratio, either by reducing shoot growth rate or by increasing root growth relative to shoot growth was correlated with the ability to withstand transplant shock in diverse field environments (Franco et al., 2001; Leskovar, 1998).

Received for publication 20 June 2001. Accepted for publication 11 Dec. 2001 We gratefully acknowledged assistance of J. Roca and A. Zamora. This research was supported in part by Fundación Séneca, Exp. 00279/CV/99. Appreciation is also extended to the Texas Department of Agriculture through the TDA-TIE Program No. 459110.

${ }^{1}$ Corresponding author; e-mail josea.franco@upct.es.
In watermelons [Citrullus lanatus (Thunb.) Matsum. \& Nakai], root distribution was compared for direct seeded plants and transplants (NeSmith, 1999). Root descriptions obtained from excavations of vegetable crops, including melons, were reported by earlier work of Weaver and Bruner (1927). Genetic and environmental variation for root traits was also demonstrated for several melon genotypes (Crosby, 1999). However, root elongation of muskmelon transplants [Cucumismelo (Reticulatus Group)] as affected by irrigation method during the nursery period and after transplanting has not been investigated. Therefore, the objective of this research was to ascertain muskmelon root dynamics and shoot seedling characteristics as influenced by overhead and flotation irrigation in the nursery, and the subsequent effect of these systems on postplant root development upon transplanting in controlled or field environments.

\section{Materials and Methods}

Plant material and experimental schedule. The experiment was conducted with a Galia-type hybrid muskmelon ('Lavi'). Containerized seedlings (transplants) were grown in a nursery with two irrigation systems: overhead irrigation (OI) and flotation irrigation (FI). After the nursery period, one group of transplants was grown in a growth chamber to characterize early root development, and the second group was transplanted in the field to assess root dynamics using the minirhizotron technique.

NURSERY PERIOD. Muskmelon transplants were grown in polystyrene trays with 150 inverted pyramid cells $(4 \times 4 \mathrm{~cm}$ in cross section, $7 \mathrm{~cm}$ deep, and $50 \mathrm{~mL}$ capacity). Seeds were sown manually on 27 Mar. 2000 in a medium $(45 \mathrm{~mL})$ of 8 black peat : 2 sphagnum peat (by volume), and covered with a thin layer (5 $\mathrm{mL}$ ) of medium grade horticultural vermiculite (particles $\leq 4$ $\mathrm{mm}$ ). The main physical characteristics of the medium were as 
follows: bulk density, $210 \mathrm{~kg} \cdot \mathrm{m}^{-3}$; total pore space, $87 \%$ by volume; volume of air after irrigation, $19 \%$ by volume; and readily available water, $29 \%$ by volume. Trays were moistened and left to germinate for $4 \mathrm{~d}$ in a dark germination chamber at 21 ${ }^{\circ} \mathrm{C}$ and $95 \%$ relative humidity $(\mathrm{RH})$, and then transferred to a greenhouse with minimum/maximum temperatures of 14 to 18 / 28 to $35^{\circ} \mathrm{C}$; and minimum/maximum $\mathrm{RH}$ of $28 \%$ to $56 \% / 75 \%$ to $94 \%$, respectively. The greenhouse had only natural light, with an average midday photosynthetically active radiation $(P A R)$ of $1360 \mu \mathrm{mol} \cdot \mathrm{m}^{-2} \cdot \mathrm{s}^{-1}$.

Transplants were irrigated daily using two watering systems: overhead (OI) and flotation (FI). Irrigation was provided to maintain medium water content between $25 \%$ and $80 \%$ of waterholding capacity $(w / w)$. Irrigation was applied with a nutrient solution maintained at an electrical conductivity $\left(\mathrm{EC}_{\mathrm{w}}\right)$ of 1.30 $\mathrm{dS} \cdot \mathrm{m}^{-1}$ and $\mathrm{pH}$ 5.8. The composition of the nutrient solution was $\left(\mu \mathrm{mol} \cdot \mathrm{L}^{-1}\right): \mathrm{NO}_{3}^{-}, 4000 ; \mathrm{H}_{2} \mathrm{PO}_{4}^{-}, 3200 ; \mathrm{Cl}^{-}, 1700 ; \mathrm{SO}_{4}{ }^{2-}, 3300$; $\mathrm{HCO}_{3}^{-}, 500 ; \mathrm{Ca}^{2+}, 4100 ; \mathrm{K}^{+}, 3100 ; \mathrm{Na}^{+}, 900 ; \mathrm{Mg}^{2+}, 1000 ; \mathrm{NH}_{4}^{+}$, 500; Fe (as Fe-EDTA), 25; Mn (as Mn-EDTA), 8; Zn (as ZnEDTA), 1.2; $\mathrm{Cu}$ (as Cu-EDTA), 0.5; $\mathrm{B}$ ( as $\mathrm{Na}_{2} \mathrm{~B}_{4} \mathrm{O}_{7}$ ), 7.5; and $\mathrm{Mo}$ (as $\mathrm{NaMoO}_{4} \cdot 2 \mathrm{H}_{2} \mathrm{O}$ ), 0.3. For the FI system, a bed was constructed inside the greenhouse using a galvanized metal trough $(2 \times 0.8 \times$ $0.2 \mathrm{~m}$ ) lined with $0.2-\mathrm{mm}$-thick clear polyethylene film. The flotation bed was filled to a depth of $15 \mathrm{~cm}$ with nutrient solution and, at each irrigation, trays were maintained floating for $\approx 15 \mathrm{~min}$ and then removed from the floatbed. Fertilizer and tap water were added every 2 or $3 \mathrm{~d}$ to adjust nutrient concentrations to the $\mathrm{EC}_{\mathrm{w}}$ nutrient solution. For the OI system, trays were watered in two to four passes using a boom attached to a backpack $\mathrm{CO}_{2}$ sprayer with tree nozzles with similar characteristics to those used in commercial nurseries. Standard phytosanitary treatments for muskmelons were applied during the nursery period. A randomized complete-block design with irrigation systems replicated four times was used.

TransPlant GRowTH. Twelve transplants (three randomly selected per tray) per irrigation system were sampled destructively at 15, 25, and $36 \mathrm{~d}$ after seeding (DAS), 36 DAS being the end of the nursery period. Transplants were removed from the trays with forceps and shoots were cut off at the medium surface. Stem length, leaf area and fresh weight (FW) of stem and leaves were measured immediately after cutting as described by Franco et al. (1997); dry weight (DW) of stems and leaves were determined by drying at $65^{\circ} \mathrm{C}$ for $3 \mathrm{~d}$. Roots were washed in water and partitioned into their components (Leskovar and Stoffella, 1995; Nicola, 1998): taproot (of embryonic origin), laterals (arising from the taproot), and basals (arising from the basal region of the hypocotyl). Total root length was measured using the digital image analysis system WinRhizo LA 1600 (Régent Instruments Inc., Québec, Canada). Roots were blotted and FWs and DWs were determined as described by Franco et al. (1993). At the end of the experiment, leaves were analyzed for their macronutrient levels. Total $\mathrm{N}$ content was determined by the Kjeldahl method, and $\mathrm{P}, \mathrm{K}, \mathrm{Ca}$, and $\mathrm{Mg}$ contents by atomic absorption spectrophotometry (Franco et al., 1993,1999). Midday xylem water potential at the base of the stem of transplants $\left(\Psi_{\text {stem }}\right)$ was measured with a pressure chamber (model 3000; Soilmoisture Equipment Corp., Santa Barbara, Calif.) at 15, 25, and 36 DAS, the last at the end of the nursery period. Twelve transplants (three randomly selected per tray) per irrigation system were excised at the base of the stem and were inserted into a portable pressure chamber and $\Psi_{\text {stem }}$ was measured by standard procedures.

GROWTH CHAMBER AND ROOT GROWTH. To study early root development after the nursery period, OI and FI transplants were planted immediately into transparent containers (round acrylic tubes $8 \mathrm{~cm}$ diameter, $100 \mathrm{~cm}$ height, and $\approx 5 \mathrm{~L}$ volume) filled with a medium of 2 sand : 7 black peat : 1 sphagnum peat (by volume). The characteristics of the medium were as follows: bulk density, $290 \mathrm{~kg} \cdot \mathrm{m}^{-3}$; total pore space, $76 \%$ by volume; volume of air after irrigation, $17 \%$ by volume; easily available water, $26 \%$ by volume; N, P, K concentration $\left(\mathrm{mg} \cdot \mathrm{L}^{-1}\right): 210 \mathrm{~N}, 90 \mathrm{P}$, and $220 \mathrm{~K}$. The containers were kept in a growth chamber until the end of the experiment (18d); the environmental conditions were minimum/ maximum average temperatures of $20 / 28^{\circ} \mathrm{C}$, RH ranged between $50 \%$ and $95 \%$, and a $16-\mathrm{h}$ photoperiod $\left(P A R\right.$ of $\left.320 \mu \mathrm{mol} \cdot \mathrm{m}^{-2} \cdot \mathrm{s}^{-1}\right)$. The light source was fluorescent lamps (F58W/GRO-LUX; Sylvania, Munich, Germany). Irrigation nutrient solution was supplied via outlets of a spaghetti-type emitter (Netafim, Iftach, Israel), arranged for each container at a discharge rate of $1 \mathrm{~L} \cdot \mathrm{h}^{-1}$. The composition of the nutrient solution was $\left(\mu \mathrm{mol} \cdot \mathrm{L}^{-1}\right): \mathrm{NO}_{3}{ }^{-}$, 4700; $\mathrm{H}_{2} \mathrm{PO}_{4}^{-}, 4600 ; \mathrm{Cl}^{-}, 3800 ; \mathrm{SO}_{4}{ }^{2-}, 2500 ; \mathrm{HCO}_{3}^{-}, 500 ; \mathrm{Ca}^{2+}$, 4200; $\mathrm{K}^{+}, 3600 ; \mathrm{Na}^{+}, 3000 ; \mathrm{Mg}^{2+}, 1500 ; \mathrm{NH}_{4}^{+}, 500 ; \mathrm{Fe}, 26.8 ; \mathrm{Mn}$, $10.9 ; \mathrm{Zn}, 1.8 ; \mathrm{Cu}, 0.8 ; \mathrm{B}, 11.8$; and $\mathrm{Mo}, 0.4$. Properties of the solution were $\mathrm{EC}_{\mathrm{w}} 2.36 \mathrm{dS} \cdot \mathrm{m}^{-1}$ and $\mathrm{pH}$ 5.8. To compensate for transpiration based on plant size, amounts applied were increased over time from 150 to $450 \mathrm{~mL} \cdot \mathrm{d}^{-1}$.

Four transplants per replication of the nursery irrigation systems were planted separately in individual transparent containers using a completely randomized design. Containers were covered with a black polyethylene sheet and insulating material to prevent light influencing and becoming heated (Franco and Abrisqueta, 1997). These transparent containers were marked previously with a $1 \times 1-\mathrm{cm}$ matrix. Root length was measured every $2 \mathrm{~d}$ for $18 \mathrm{~d}$. At each measurement time, the polyethylene sheet was removed and root length was taken at $1 \mathrm{~cm}$ increments through the transparent sides of the containers.

Field EXPERIMENT. The field trial was conducted in Campo de Cartagena, on the Mediterranean coast of Spain (lat. $37^{\circ} 45^{\prime} \mathrm{N}$; long. $0^{\circ} 59^{\prime} \mathrm{W}$; altitude $105 \mathrm{~m}$ ). The climate of the region is mild, with slightly rainy winters and hot dry summers. During the experimental period minimum/maximum temperatures were 16 to $24 / 26$ to $39^{\circ} \mathrm{C}$, and minimum/maximum $\mathrm{RH}$ was $11 \%$ to $63 \%$ / $63 \%$ to $96 \%$. The soil was a fine, carbonatic, calcareous, thermic Typic Haplocalcid with the soil profile deeper than $2 \mathrm{~m}$, with a silt loam texture with an EC of the saturation extract of $2.1 \mathrm{dS} \cdot \mathrm{m}^{-1}$.

Cultural practices common to commercial muskmelon production in the area were followed. Tillage preparation before planting consisted of chisel plowing to $\approx 25 \mathrm{~cm}$ deep, disk harrowing, rototilling, and marking rows at $2 \mathrm{~m}$ apart in $20-\mathrm{cm}$ raised beds and $1.25 \mathrm{~m}$ width with a furrow opener. A preplant fertilizer $(10 \mathrm{~N}-4.4 \mathrm{P}-8.3 \mathrm{~K})$ was broadcast and incorporated at $340 \mathrm{~kg} \cdot \mathrm{ha}^{-1}$. Transplants, $36 \mathrm{~d}$ old, grown in the nursery under OI and FI irrigation, were planted into raised beds at a plant population of 10,000 plants/ha on 2 May 2000. Before transplanting to the field, the transplants were watered to $100 \%$ medium water holding capacity.

Drip irrigation lines, with pressure-compensated emitters at 4 $\mathrm{L} \cdot \mathrm{h}^{-1}$ spaced at $0.5 \mathrm{~m}$ intervals along the line, were placed at the center of the beds. In each bed, transplants (one per emitter) were planted adjacent to each emitter in a row and within $15 \mathrm{~cm}$ of the side of the trickle line. Frequency and amount of irrigation and fertilization through the drip system followed the regimes recommended for the area during the spring-summer growing season. Tensiometers were installed in the row midway between plants at a depth of $30 \mathrm{~cm}$. All plants were irrigated identically, maintain- 
ing the soil matric potential between -20 and $-25 \mathrm{kPa}$. No differences in flow rate were found between emitters. The N:P:K ratio of the irrigation water was modified during cultivation as follows: at planting, 1:2:0.5; at the beginning of growth, 1:2:1; first flower, 1:1.5:1.5; at the beginning of fruiting, 1:1:1.5; and full fruiting, 1:0.5:2. During the course of the experiments, plants did not exhibit nutrient deficiency symptoms. Water with an average $\mathrm{EC}_{\mathrm{w}}$ of $2.4 \mathrm{dS} \cdot \mathrm{m}^{-1}$ was applied daily throughout the experiment to encourage adequate leaching to prevent salt accumulation in the root zone. The soil was sampled frequently in the root zone and the $\mathrm{EC}_{\mathrm{e}}$ was determined by the 1:5 (1 soil : 5 distilled water) dilution method. A preplant application of the herbicide sodium 2-[(1-naphthalenylamino) carbonyl] benzoate (naptalamsodium, $24 \%$ by volume) at an a.i. rate of $3 \mathrm{~L} \cdot \mathrm{ha}^{-1}$ followed by early hand weeding was used to control weeds throughout the course of the experiment. All necessary insect and disease control measures were applied during the experiment. The experiment was a randomized complete-block design with three replications of 20 plants per nursery irrigation system.

RoOT DYNAMICS WITH MINIRHIZOTRONS. The minirhizotron used for the root dynamic study was that described by Franco and Abrisqueta (1997). Three minirhizotron tubes were placed just under each plant row. Round transparent acrylic tubes, $2 \mathrm{~m}$ long, $80 \mathrm{~mm}$ external diameter and $74 \mathrm{~mm}$ internal diameter, were installed permanently at a $45^{\circ}$ angle to the soil surface to prevent abnormal growth of the roots at the tube-soil interface (McMichael and Taylor, 1987). The total length of the buried tube was $1.4 \mathrm{~m}$, reaching a vertical depth of $1 \mathrm{~m}$. The center of the buried tube coincided with the vertical projection of the dripper line, just under an emitter.

It is well established that root growth with drip irrigation is limited to the wetted zone of the soil, therefore, it justifies the location of tubes only in that area. The part of the tube protruding from the soil surface was closed with a rubber stopper and covered with a black polyethylene sheet and an insulating material to block light from entering the tube and to prevent it from becoming hot, both of which would have favored the absence of roots around the tube near the soil surface (McMichael and Taylor, 1987). To ensure adequate soil-tube contact and to minimize the effects of the installation procedure on root growth, a hole slightly smaller in diameter than the tube was made in a two-step process. First an initial hole was drilled with a $65-\mathrm{mm}-$ diameter auger; then, the final hole was made by reaming to 79.9 $\mathrm{mm}$ with a coring tube. After this coring, the walls of the hole were misted with water and the minirhizotron tube was inserted manually. The tubes were installed on 15 Mar. 2000. Transplants were planted on 2 May and root counting started on 17 May. Seven measurements were made between 2 May and 15 Aug. at biweekly intervals. Roots were observed by means of a magnifying lens made out of a photographic lens (Will Wetzlar Wilon 1:4.5/ 50; Will Heerbrugg, Heersbagg, Switzerland) and a microscope eyepiece (Kpl W 12.5 mm; Carl Zeiss, Oberkochen, Germany) connected together by sliding polyvinyl chloride tubes for focusing (Franco and Abrisqueta, 1997). All roots were counted in each $5-\mathrm{cm}$ tube section. Data were then grouped in sections corresponding to about four layers in the soil: 0 to 25,25 to 50,50 to 75 , and 75 to $100 \mathrm{~cm}$ deep. The root length density (RLD), expressed in centimeters of root per cubic centimeter of soil, was obtained applying the formula used by Upchurch and Ritchie (1983).

FRUIT YIELD AND QUALITY. Marketable melons were harvested at the mature stage. Harvesting ended $105 \mathrm{~d}$ after planting (DAP), when the field experiment was concluded. FW, equatorial diameter, total soluble solids (TSS), and reducing sugars (RS) were determined for all harvested fruit. For the last two parameters, a fruit homogenate was obtained by separating the pericarp and seeds through centrifugation, and the supernatant analyzed by standard procedures (Franco et al., 1993).

STATISTICAL ANALYSIS. All data sets were subjected to analysis of variance (ANOVA) using Statgraphics program version 7.0 (STSC, Rockville, Md.). Minirhizotron root count data were first checked to see whether they conformed with the assumptions of the ANOVA before transformation; normality, homogeneity of variances, independence of mean and variances, and additivity (Snedecor and Cochran, 1980). Variances were positively correlated with the means, a condition that violates the assumptions necessary for ANOVA. Transformations (best fit $\mathrm{y}=\mathrm{x}^{0.3}$ ) based on Taylor's power law (Glenn et al., 1987) were used to stabilize the variance and minimized the correlation between variances and means.

\section{Results and Discussion}

NURSERY PERIOD. Lateral root elongation was greater for OI transplants than for FI transplants at 15 and 25 DAS, but similar at 36 DAS (Fig. 1A), while basal root elongation was greater for OI than for FI transplants throughout the nursery period (Fig. 1B). OI may provide uniform moisture levels around the hypocotyl,
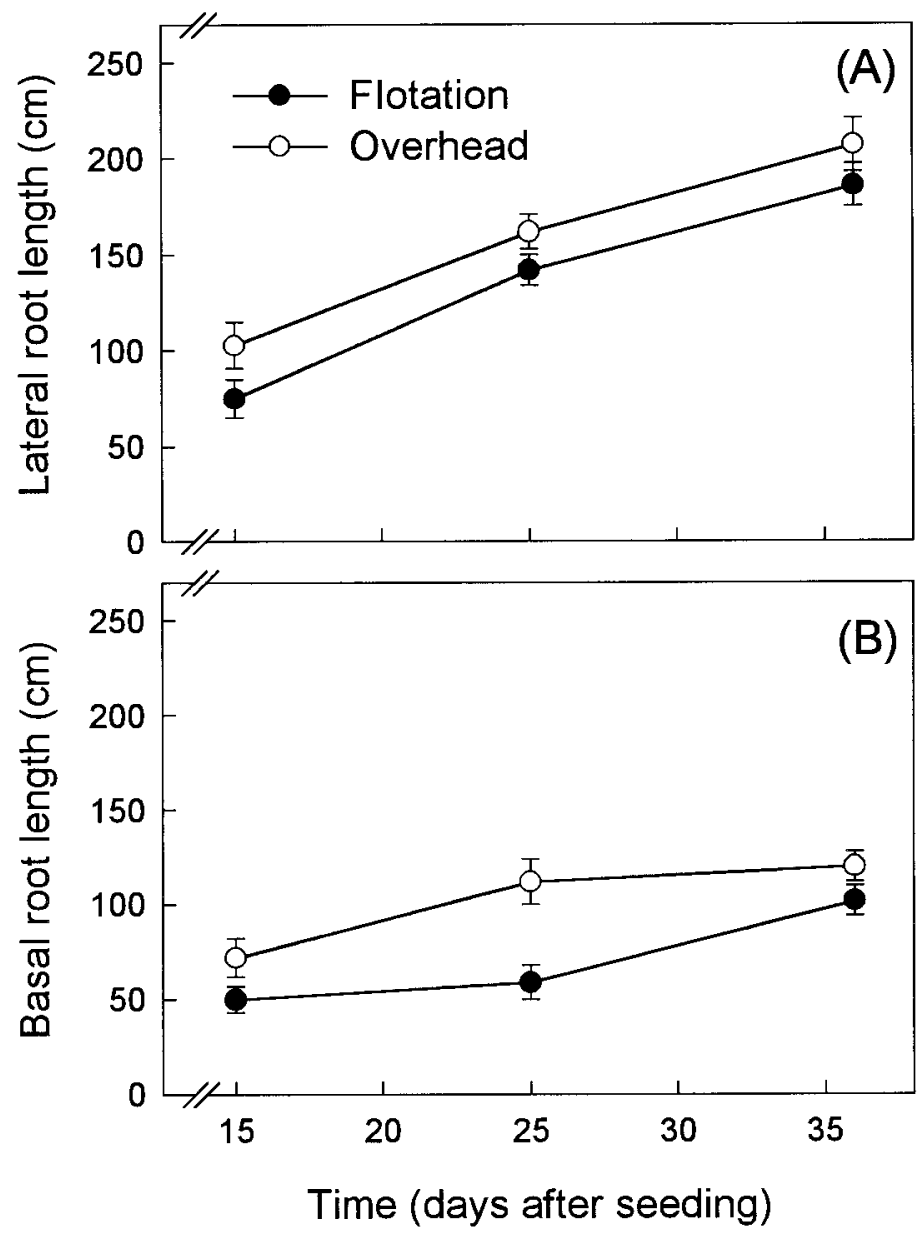

Fig. 1. Length of (A) lateral and (B) basal roots of 'Lavi' muskmelon transplants in response to greenhouse irrigation system (flotation or overhead) during the nursery period. Vertical bars indicate SE $(n=12)$ and legend in $\mathbf{A}$ applies to $\mathbf{B}$. 

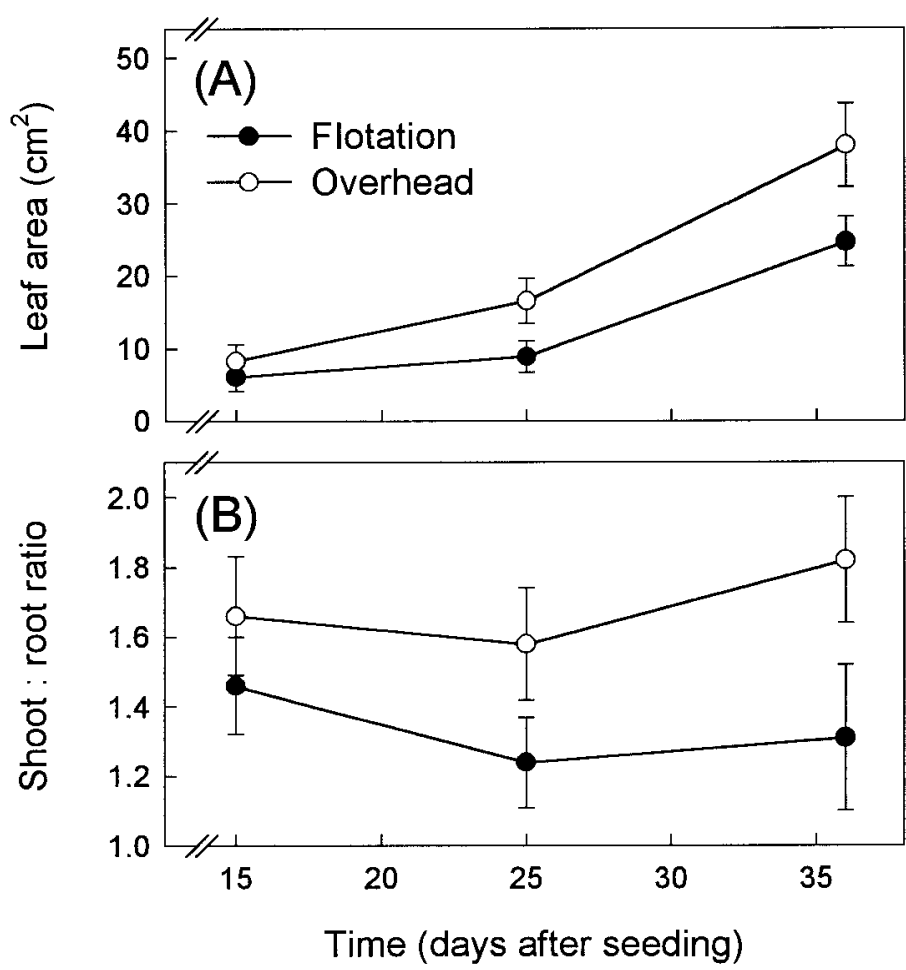

Fig. 2. (A) Leaf area and (B) shoot to root FW ratio of 'Lavi' muskmelon transplants in response to greenhouse irrigation system (flotation or overhead) during the nursery period. Vertical bars indicate SE $(n=12)$ and legend in $\mathbf{A}$ applies to $\mathbf{B}$.

promoting more basal than lateral root elongation. OI promoted early basal root growth, whereas FI promoted basal root elongation late in development (36 DAS). The newly emerged basal roots may be strong sinks for assimilates and can constitute important growth components upon transplanting in the field. The importance of basal roots to improve stand establishment and plant growth has been recognized in other vegetable species (Leskovar, 1998; Leskovar and Stoffella, 1995).

Leaf area (Fig. 2A) and shoot to root ratio (Fig. 2B) were also greater for OI transplants than for FI transplants between 25 and 36 DAS. The higher shoot to root ratio for OI transplants was mainly due to an increase in leaf weight which is associated with leaf area (Fig. 2A), since stem length, and root FW and DW were unaffected by irrigation systems (Table 1). OI transplants had a larger leaf area (Fig. 2A) and higher shoot FW and DW (Table 1) than FI transplants. Other studies with containerized transplants grown in polystyrene trays have reported higher leaf weights resulting from overhead irrigation on tomato and pepper. For example shoot to root ratio was greater for OI than for FI jalapeño pepper transplants at the end of the nursery period (Leskovar and Heineman, 1994). When drought stress was used to harden and prevent stem elongation in fresh market tomato transplants grown with FI, there was a decrease in shoot to root ratio, but leaf enlargement and shoot DW were negatively affected (Leskovar et al., 1994). A reduction of shoot to root ratio of transplants, either by shoot growth reduction or by larger root growth relative to shoot growth, was correlated with the ability to withstand transplant shock (Franco et al., 2001; Leskovar, 1998).

Stem water potential $\left(\Psi_{\text {stem }}\right)$ was lower for FI transplants than for OI transplants $(-0.95$ vs. $-0.88 \mathrm{MPa})$ only at $15 \mathrm{DAS}$, but similar at 25 and 36 DAS (data not presented). Leskovar and Heineman (1994) reported that FI pepper transplants maintained a lower shoot water potential than OI transplants between 20 and 41 DAS. Leaf $\mathrm{K}$ concentration was higher for FI than for OI transplants at $36 \mathrm{DAS}$, but $\mathrm{N}, \mathrm{P}, \mathrm{Ca}$, and $\mathrm{Mg}$ concentrations were similar (Table 2). It is well known that $\mathrm{K}$ plays a key role in osmoregulation processes (Marschner, 1990). We speculate that the decrease in $\Psi_{\text {stem }}$ and the increase in K concentration could be due to a transient early water stress in FI transplants; however, since we have partial data, this hypothesis deserves further investigation.

GrowTH CHAMBER STUDY. After transplanting into containers in the growth chamber, root elongation was significantly greater for FI than for OI transplants, particularly between 4 and 14 DAP (Fig. 3). The greater root elongation during early development for FI transplants may be important for increased plant survival and the ability to withstand transplant shock. For dicot species, the capacity of a containerized seedlings to overcome transplant shock and become rapidly established in a field environment following transplanting depends, among other factors, on the capacity of the preexisting roots to grow rapidly and to rapidly regenerate new lateral and basal roots (Leskovar, 1998; Leskovar

Table 1. Influence of nursery irrigation system on shoot and root growth of 'Lavi' muskmelon transplants $36 \mathrm{~d}$ after seeding. ${ }^{\mathrm{Z}}$

\begin{tabular}{|c|c|c|c|c|c|}
\hline \multirow{2}{*}{$\begin{array}{l}\text { Irrigation } \\
\text { system }\end{array}$} & \multirow{2}{*}{$\begin{array}{c}\text { Stem } \\
\text { length }(\mathrm{cm})\end{array}$} & \multicolumn{2}{|c|}{ Fresh wt $(\mathrm{g})$} & \multicolumn{2}{|c|}{ Dry wt (g) } \\
\hline & & Shoot & Root & Shoot & Root \\
\hline Flotation (FI) & 9.5 & 1.62 & 1.23 & 0.17 & 0.11 \\
\hline Overhead (OI) & 11.1 & 2.90 & 1.59 & 0.28 & 0.14 \\
\hline Significance & NS & $* *$ & NS & $* *$ & NS \\
\hline
\end{tabular}

${ }^{\mathrm{z}}$ Values represent the overall mean of four replications of three transplants.

Ns, ** Nonsignificant or significant by $\mathrm{F}$ test at $P \leq 0.01$, respectively.

Table 2. Influence of nursery irrigation system on leaf macronutrients (percentage DW) of 'Lavi' muskmelon transplants $36 \mathrm{~d}$ after seeding.

\begin{tabular}{lcccc}
\hline \hline Irrigation & \multicolumn{4}{c}{ Mineral nutrient } \\
\cline { 2 - 5 } system & $\mathrm{N}_{\text {total }}$ & $\mathrm{P}$ & $\mathrm{K}$ & $\mathrm{Ca}$ \\
\hline Flotation (FI) & 5.15 & 0.52 & 3.31 & 3.27 \\
Overhead (OI) & 5.63 & 0.49 & 2.90 & 3.06 \\
Significance & $\mathrm{NS}$ & $\mathrm{NS}$ & $\mathrm{Ng}$ \\
\hline
\end{tabular}

${ }^{\mathrm{z}}$ Values represent the overall mean of four replications of three transplants.

Ns, ${ }^{*}$ Nonsignificant or significant by $\mathrm{F}$ test at $P \leq 0.05$, respectively. 


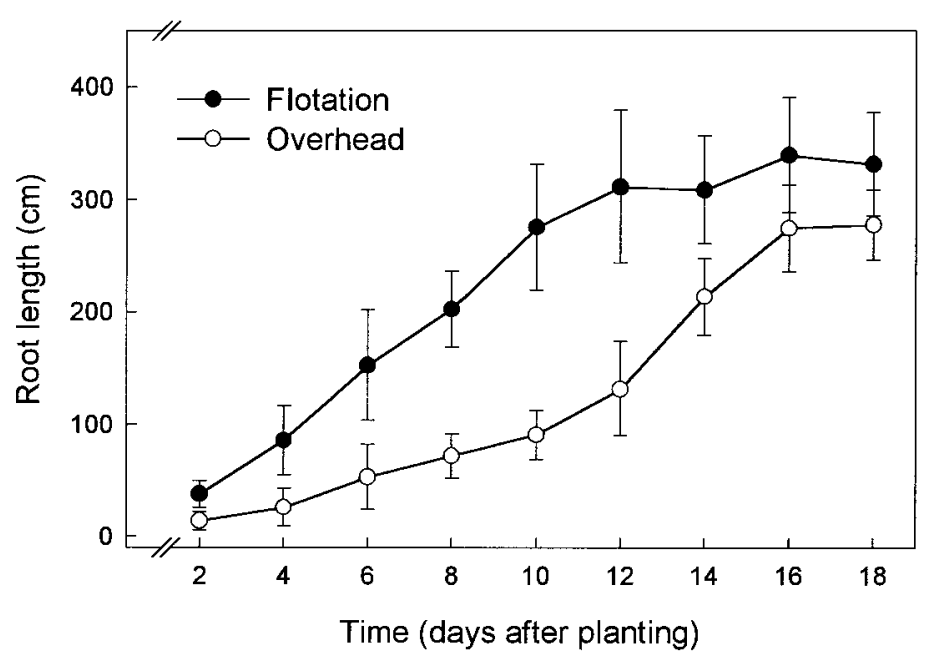

Fig. 3. Root length of 'Lavi' muskmelon after planting (measured through the sides of transparent containers in the growth chamber). Transplants were irrigated by flotation or overhead irrigation during a 36-d nursery period. Vertical bars indicate SE $(\mathrm{n}=12)$.

and Stoffella, 1995). In muskmelons, increased early root length and vigor may also provide a tolerance mechanism against soil diseases, such as root rot vine decline (Monosporascus cannonballus Pollack \& Uecker), that cause vine decline (Crosby, 1999).

FiELD STUDY. After transplanting in the field, RLD was greater in the uppermost layer of the soil profile ( 0 to $25 \mathrm{~cm}$ deep) for FI transplants than for OI transplants (Fig. 4), particularly between 30 and 80 DAS. Excavations of melon roots by Weaver and Bruner (1927), revealed a taproot of $45 \mathrm{~cm}$ with four to five laterals extending up to $92 \mathrm{~cm}$ in the top 10 to $30 \mathrm{~cm}$ of soil during the first 28 DAS. Between a 25 and $75 \mathrm{~cm}$ depth, irrigation systems during the nursery period did not affect RLD after transplanting, while root development was minimal in both transplants when measured between a 75 and $100 \mathrm{~cm}$ depth. At the end of the experimental period (105 d), RLD was not significantly different in whole soil profile for OI and FI transplants.

The greater early root growth following planting for FI transplants than for OI transplants (with a RLD practically three times greater at 45 DAP) may indicate a greater root capacity for water and mineral nutrient uptake, and soil gas exchange characteristics. Although yields were statistically similar, there was a numerical trend towards increased yield for FI than OI transplants (Table 3). In watermelon transplants, greater root length density was found in the upper $30 \mathrm{~cm}$ of soil between 28 and 49 DAS (NeSmith, 1999). Greater root growth, and possibly root function, in transplants may have resulted in greater yields in comparison to direct seeded plants in peppers (Leskovar and Cantliffe,

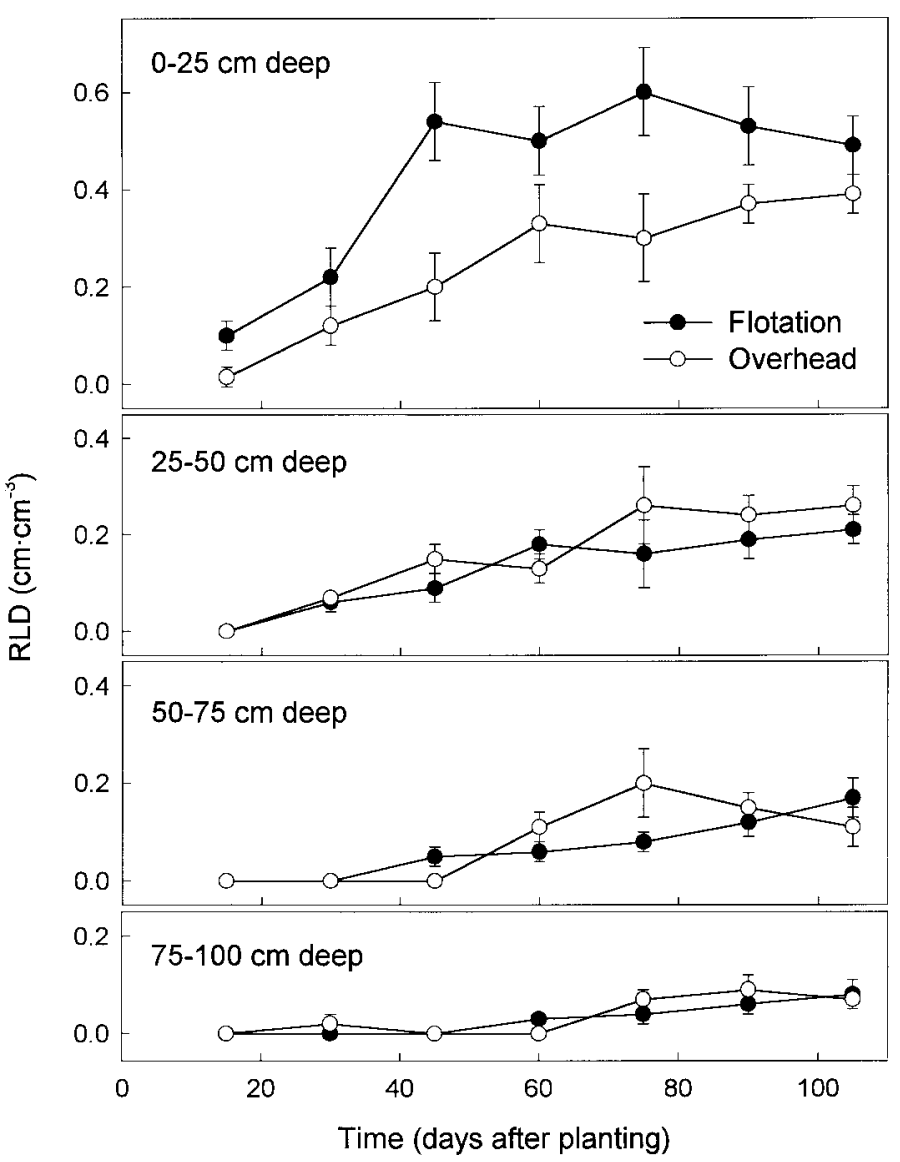

Fig. 4. Postplanting root length density (RLD) in 25-cm increments over a 100 $\mathrm{cm}$ soil depth for transplants of 'Lavi' muskmelon. Transplants were irrigated by flotation or overhead irrigation during a 36-d nursery period. Vertical bars indicate SE $(n=9)$.

1993), muskmelons (NeSmith, 1997), and watermelons (NeSmith, 1999). Fruit FW, equatorial diameter, and organoleptic characteristics determined by total soluble solids and reducing sugars were unaffected by irrigation systems (Table 3 ). It is plausible that rapid proliferation of transplant roots in the upper soil depth enhanced earlier mineral nutrient acquisition and the efficiency of water uptake, as reported by other studies (NeSmith, 1994, 1999; Wien et al., 1993).

In conclusion, the irrigation method for muskmelon transplants influenced early root development in the nursery and postplanting root dynamics. The increase in shoot growth and early root growth for OI transplants in the nursery did not enhance subsequent root growth in the growth chamber and field. Even though FI transplants had slightly lower root elongation in the

Table 3. Marketable yield and fruit characteristics of 'Lavi' muskmelon grown in the field as affected by irrigation system during the nursery period. ${ }^{\mathrm{z}}$

\begin{tabular}{|c|c|c|c|c|c|}
\hline \multirow[b]{2}{*}{$\begin{array}{l}\text { Irrigation } \\
\text { system }\end{array}$} & \multirow[b]{2}{*}{$\begin{array}{c}\text { Marketable } \\
\text { yield } \\
\left(\mathrm{kg} \cdot \mathrm{m}^{-2}\right)\end{array}$} & \multicolumn{4}{|c|}{ Fruit characteristics } \\
\hline & & $\begin{array}{l}\text { Fresh wt } \\
\text { (g) }\end{array}$ & $\begin{array}{l}\text { Equatorial } \\
\text { diam } \\
(\mathrm{cm})\end{array}$ & $\begin{array}{c}\text { Total } \\
\text { soluble } \\
\text { solids }(\%)\end{array}$ & $\begin{array}{c}\text { Reducing } \\
\text { sugars } \\
\left(\mathrm{mg} \cdot \mathrm{g}^{-1} \text { fresh } \mathrm{wt}\right)\end{array}$ \\
\hline Flotation (FI) & 4.12 & 896 & 38.9 & 13.2 & 25.6 \\
\hline Overhead (OI) & 3.80 & 904 & 39.5 & 12.8 & 23.1 \\
\hline Significance & NS & NS & NS & NS & NS \\
\hline
\end{tabular}

${ }^{\mathrm{z}}$ Values represent the overall mean of three replications of 20 plants.

${ }^{\mathrm{N} N}$ Nonsignificant by $\mathrm{F}$ test. 
nursery, preexisting roots appeared to have a greater capacity for root regeneration since root length increased at a faster rate than OI transplants when measured in the growth chamber and minirhizotrons in the field environment. This adaptive root growth response may be critical for rapid acclimation upon transplanting.

\section{Literature Cited}

Biernbaum, J.A. and N.B. Versluys. 1998. Water management. HortTechnology 8:504-509.

Crosby, K. 1999. Genetic variation in melon root structure and Monosporascus cannonballus tolerance. PhD diss. Texas A\&MUniv., College Station.

Franco, J.A. and J.M. Abrisqueta. 1997. A comparison between minirhizotron and soil coring methods of estimating root distribution in young almond trees under trickle irrigation. J. Hort. Sci. 72:797-805.

Franco, J.A., S. Bañón, J.A. Fernández, and D.I. Leskovar. 2001. Effect of nursery regimes and establishment irrigation on root development of Lotus creticus seedlings following transplanting. J. Hort. Sci. Biotechnol. 76:174-179.

Franco, J.A., C. Esteban, and C. Rodríguez. 1993. Effects of salinity on various growth stages of muskmelon cv. Revigal. J. Hort. Sci. 68:899904.

Franco, J.A., J.A. Fernández, S. Bañón, and A. González. 1997. Relationship between the effects of salinity on seedling leaf area and fruit yield of six muskmelon cultivars. HortScience 32:642-644.

Franco, J.A., P.J. Pérez-Saura, J.A. Fernández, M. Parra, and A.L. García. 1999. Effect of two irrigation rates on yield, incidence of blossom-end rot, mineral content and free amino acid levels in tomato cultivated under drip irrigation using saline water. J. Hort. Sci. Biotechnol. 74:430-435.

Frantz, J.M. and G.E. Welbaum. 1995a. A comparison of four cabbage transplant production systems, p. 169-174. Proc. $4^{\text {th }}$ Natl. Symp. of Stand Establishment for Hort. Crops.

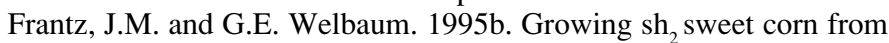
transplants, p. 199-202. Proc. $4^{\text {th }}$ Natl. Symp. of Stand Establishment for Hort. Crops.

Glenn, D.M., M.W. Brown, and F. Takeda. 1987. Statistical analysis of root count data from minirhizotrons, p. 81-87. In: H.M. Taylor (ed.). Minirhizotron observation tubes: Methods and applications for mea- suring rhizosphere dynamics. Amer. Soc. Agron., Madison, Wis. Leskovar, D.I. 1998. Root and shoot modification by irrigation. HortTechnology 8:510-514.

Leskovar, D.I. and D.J. Cantliffe. 1993. Comparison of plant establishment method, transplant or direct-seeding, on growth and yield of bell pepper. J. Amer. Soc. Hort. Sci. 118:17-22.

Leskovar, D.I., D.J. Cantliffe, and P.J. Stoffella. 1994. Transplant production systems influence growth and yield of fresh market tomatoes. J. Amer. Soc. Hort. Sci. 119:662-668.

Leskovar, D.I. and R.R. Heineman. 1994. Greenhouse irrigation systems affect growth of 'TAM-Mild Jalapeño-1' pepper seedlings. HortScience 29:1470-1474.

Leskovar, D.I. and P.J. Stoffella. 1995. Vegetable seedling root systems: Morphology, development, and importance. HortScience 30:11531159.

Marschner, H. 1990. Mineral nutrition of higher plants. Academic Press, London.

McMichael, B.L. and H.M. Taylor. 1987. Applications and limitations of rhizotrons and minirhizotrons, p. 1-13. In: H.M. Taylor (ed.). Minirhizotron observation tubes: Methods and applications for measuring rhizosphere dynamics. Amer. Soc. Agron., Madison, Wis.

NeSmith, D.S. 1994. Transplant age has little influence on yield of muskmelon (Cucumis melo L.). HortScience 29:916.

NeSmith, D.S. 1997. A comparison of yields and yield components from different muskmelon (Cucumis melo L.) production systems. J. Veg. Crop Production 3:37-45.

NeSmith, D.S. 1999. Root distribution and yield of direct seeded and transplanted watermelon. J. Amer. Soc. Hort. Sci. 124:458-461.

Nicola, S. 1998. Understanding root systems to improve seedling quality. HortTechnology 8:544-549.

Snedecor, G.W. and W.G. Cochran. 1980. Statistical methods. The Iowa State Univ. Press, Ames.

Upchurch, D.R. and J.T. Ritchie. 1983. Root observations using a video recording system in mini-rhizotrons. Agron. J. 73:1009-1015.

Weaver, J.E. and W.E. Bruner. 1927. Root development of vegetable crops. McGraw-Hill, New York.

Wien, H.C., P.L. Minotti, and V.P. Grubinger. 1993. Polyethylene mulch stimulates early root growth and nutrient uptake of transplanted tomatoes. J. Amer. Soc. Hort. Sci. 118:207-211.

Wyatt, J.E. 1998. Tomato transplant production using the float system and cupric hydroxide. HortTechnology 8:366-369. 